\title{
Correlation of IL-8 and C - Reactive Protein Serum Levels with the Severity of Inflammatory Acne Vulgaris: A Comparative Study
}

\author{
Rania H E. Mohammed ${ }^{1}$, Ghada F. Mohammed ${ }^{1}$, Alaael-din S. Abd-el-hamid ${ }^{2}$ \\ Moustafa M. K. Eyada ${ }^{1}$ \\ ${ }^{1}$ Department of Dermatology and Venereology \\ ${ }^{1 *}$ Department of Dermatology and Venereology, Faculty of Medicine, Suez Canal University \\ Ismailia, Egypt. \\ ${ }^{2}$ Department of clinical pathology, Faculty of Medicine, Suez Canal University, Ismailia, Egypt \\ Rokahassan_80@yahoo.com \\ 1*Dr_Ghada77@hotmail.com \\ dralaasaad@yahoo.com \\ Meyada@yahoo.com
}

\begin{abstract}
:
Background: Inflammatory Acne vulgaris (IAV) involves high Interleukin-8 (IL-8) serum level. To date, no study was conducted to highlight the correlation of IL-8 and C-reactive protein (CRP) with IAV.

Objective: this study was conducted to investigate the correlation of IL-8 and CRP serum levels with IAV regarding the severity of the disease.

Materials and Methods: Sera of 68 patients with IAV and 70 gender and age matched healthy volunteers were enrolled. IL-8 and CRP were measured in patients' sera with enzyme linked immune sorbent assay (ELISA). The levels were correlated with the severity of the disease using Global Evaluation Acne (GEA) scale.

Results: IL-8 and CPR serum levels in patients with IAV were significantly higher than controls $(p<0.05)$. There were high statistically significant differences of $I L-8$ and CPR levels with severity of disease ( $p<0.05)$.

Conclusion: In IAV, IL-8 and CRP are proportionally correlating to the severity of inflammatory acne vulgaris. Blocking IL-8 and CPR production may hold promise therapy in limiting the deleterious effects of IL-8 and CPR mediated inflammatory response.
\end{abstract}

Keywords: ELISA, Inflammatory Acne vulgaris, IL-8, C-reactive protein, Global Evaluation Acne scale.

\section{INTRODUCTION}

Acne vulgaris is a common skin disease of the pilosebaceous unit. It is characterized by noninflammatory lesions as seborrhea, comedones (blackheads and whiteheads); inflammatory lesions as papules, pustules and nodules; and possibly scarring [1].

The pathogenesis of inflammatory acne vulgaris (IAV) is multifactorial and complex; including hormonal, microbiological, and immunological mechanisms [2]. The interaction between Propionibacterium acnes $(P$. acnes) and infiltrated monocytes and lymphocytes also play an important role in the pathogenesis of IAV [3, 4]. Interleukin-8 (IL-8) is a CXC-type chemokine that binds to the cellular seven transmembrane domain $\mathrm{G}$ protein-coupled receptors known as CXCR1 and CXCR2 [5, 6]. IL-8 is a potent proinflammatory chemotactic factor that predominantly exerts its chemotactic effects on neutrophils [6-8].

IL-8 is produced by activating blood monocytes and tissue macrophages such as Kupffer cells (specialized tissue macrophage). It acts primarily as a co-stimulant for Th1 cells and induces the production of IFN- $\gamma$, IL-2 and granulocyte macrophage colony stimulating factor (GM-CSF). High IL-8 level is associated with $P$. acnes and $P$. acnes elected Kupffer cells [4]. Also macrophages enhance liver to synthesize $C$ reactive protein (CRP) which is considered as a marker of inflammation [9-10] and is associated with acne [11-12]. CRP induces IL-8 mRNA secretion from human blood monocytes [13]. 
As IL-8 and CRP association with IAV are approved, this study was conducted to investigate whether these associations were correlated proportionally with the severity of the disease or not.

\section{OBJECTIVE}

This study was conducted to investigate the correlation between serum high level of IL-8 and CRP with the severity of the disease.

\section{SubJECTS AND METHODS}

\subsection{Subjects}

This descriptive comparative study was carried out in Dermatology outpatient clinic, Suez Canal University Hospital for a period of 6 months in accordance with the guidelines of the Helsinki Declaration, and was performed after obtaining the informed consent from all parents of the children and patients.

Out of 157 patients with IAV; 73 excluded because either, having pregnancy, lactating women, receiving medical treatment, having other skin diseases, having other systemic diseases or those who refused to participate. By simple randomization of 84 patients with IAV eligible to participate in the study, only 68 patients with IAV enrolled. Age and gender matched 70 healthy volunteers enrolled as a control group.

\subsection{Methods}

All of the studied patients were subjected to full history-taking, general and systemic examination with special emphasis on the presence or absence of IAV and staging the severity of the disease according to Global Evaluation Acne (GEA) scale [14]. Serum levels of IL-8 a CRP were measured in all subjects by ELISA (a polystyrene Microtiter plate).

\subsubsection{IL-8 assay}

The microtiter plate provided in this kit has been precoated with an antibody specific to IL-8 Standards or samples are then added to the appropriate microtiter plate wells with a biotinconjugated polyclonal antibody preparation specific for IL-8 and Avidin conjugated to Horseradish Peroxidase (HRP) was added to each microplate well and incubated. Then a TMB $\left(3,3^{\prime} 5,5^{\prime}\right.$ tetramethyl-benzidine) substrate solution was added to each well. Only those wells that contain IL-8, biotin-conjugated antibody and enzyme-conjugated Avidin would exhibit a change in color. The enzyme substrate reaction was terminated by the addition of a sulphuric acid solution and the color change was measured spectrophotometrically at a wavelength of $450 \mathrm{~nm} \pm 2 \mathrm{~nm}$. The concentration of IL-8 in the samples was then determined by comparing the O.D. of the samples to the standard curve [15].

\subsubsection{CRP assay}

Wells of the microtitre plate were coated with polyclonal antibodies against CRP. Firstly in incubation, the CRP in the samples was bound to the coated polyclonal rabbit antibodies. By washing step, all unbound substances removed. In a second incubation step, we added Peroxidase-labeled CRP antibody. After another washing step, all unbound substances were removed; the solid phase was incubated with the substrate, Tetramethylbenzidine (TMB). An acidic stopping solution was then added. The color converted to yellow. Yellow color's intensity was directly proportional to the concentration of CRP in the sample. A dose response curve of the absorbance (at $450 \mathrm{~nm}$ ) unit vs. concentration was generated. CRP, present in the patient samples, was determined directly from this calibration curve [16]

\subsection{Statistical Analysis}

Statistical analysis was carried out using computer program SPSS version 16 (Statistical Package for the Social Science; SPSS; Inc., Chicago, IL, USA). A probability value (p-value) $<0.05$ was considered statistically significant.

\section{ReSults}

In 138 subjects, there were $(61.8 \%)$ females and $(38.2 \%)$ males with a mean age of $20.6 \pm 3.7$ years. Moderate IAV appeared in 38 patients (55.9\%), 12 patients with mild and other 12 patients with severe form were in equal percent with $(17.6 \%)$. Almost clear cases and very severe cases were $(6 \%)$ 
and (3\%) respectively. IL-8 serum levels in patients with IAV were significantly higher than control (308.4 $\pm 420.4 \mathrm{pg} / \mathrm{ml}$ versus $22.3 \pm 12.1 \mathrm{pg} / \mathrm{ml}$, respectively) [Table (1)]. CRP serum levels in patients with IAV were significantly higher than control $(6.9 \pm 4.9 \mathrm{mg} / \mathrm{l}$ versus $1.3 \pm 1.5 \mathrm{mg} / \mathrm{l}$, respectively) [Table (1)]. The relation between severity of IAV and age and gender of patient were non-significant $(\mathrm{p}=0.65$ and $\mathrm{p}=0.30$, respectively). Table (2) showed a highly statistically significant differences between IL-8 level and CRP with severity of disease ( $\mathrm{p}=0.001$ and $\mathrm{p}=0.01$, respectively). Results showed moderate positive correlation between severity of IAV with IL-8 level and CRP $(r=0.63$ and $r=0.71$ respectively), which was statistically significant $(\mathrm{p}<0.05)$. Also, a weak positive correlation between IL- 8 and CRP with duration of disease ( $r=0.29$ and $r=0.30$ respectively), which was statistically significant $(\mathrm{p}<0.05)$. In contrast, there was a weak positive correlation between severity of IAV and age and gender regarding IL-8 and CRP level. Simultaneous multiple regression was conducted to investigate the best predictor of IL-8 level and CRP. The inter-correlations of the entered variable among all study subjects were shown in [table $(3,4)]$. The combinations of variables were to predict IL-8 level and CRP included age, gender, duration of disease and severity of disease, which were $(\mathrm{F}(4.64)=13.82, \mathrm{p}<0.001$ and $\mathrm{F}(3.67)=12.83, \mathrm{p}<0.001$, respectively $)$.

The beta coefficients were presented in [table $(5,6)]$. Note that the duration and severity of the disease significantly predict IL-8 level and CRP when all four variables are included. The adjusted R2 value of IL- 8 was 0.43 this means that $43 \%$ of the variance of IL- 8 was explained by the model. That for CRP was 0.42 and means that $42 \%$ of the variance of CRP was explained by the model.

Table1. Assessment levels of $I L-8(\mathrm{pg} / \mathrm{ml})$ and CRP $(\mathrm{mg} / \mathrm{l})$ among patients with IAV and controls.

\begin{tabular}{|l|c|c|c|c|}
\hline \multirow{2}{*}{} & \multicolumn{2}{|c|}{ IL-8 (pg/ml) } & \multicolumn{2}{c|}{ CRP (mg/l) } \\
\cline { 2 - 5 } & Mean \pm SD & Range & Mean \pm SD & Range \\
\hline Patients with IAV & $308.4 \pm 420.4$ & $12-950$ & $6.9 \pm 4.9$ & $0-56$ \\
\hline Controls & $22.3 \pm 12.1$ & $11-58$ & $1.3 \pm 1.5$ & $0-6$ \\
\hline Statistical test & \multicolumn{2}{|c|}{428.5} & \multicolumn{2}{c|}{342.5} \\
\hline p-value* & \multicolumn{2}{|c|}{0.04} & \multicolumn{2}{c|}{0.02} \\
\hline
\end{tabular}

MW = Mann Whitney test was used

*significant at p-value $<0.05$.

Table2. Relation between (IL-8 and CRP) levels and disease severity.

\begin{tabular}{|c|c|c|c|}
\hline \multirow{2}{*}{\multicolumn{2}{|c|}{ Disease severity }} & IL-8 level & CRP level \\
\hline & & Mean \pm SD & Mean \pm SD \\
\hline \multicolumn{2}{|c|}{ Controls (no acne) } & $22.3 \pm 12.1$ & $2.3 \pm 1.5$ \\
\hline \multirow{5}{*}{$\begin{array}{l}\text { patients with } \\
\text { IAV }\end{array}$} & Almost clear & $12.5 \pm 0.7$ & $0.5 \pm 1.4$ \\
\hline & Mild & $29.5 \pm 16.4$ & $2.2 \pm 3.1$ \\
\hline & Moderate & $205.9 \pm 368.7$ & $4.3 \pm 4.9$ \\
\hline & Severe & $906.7 \pm 40.8$ & $5.9 \pm 1.5$ \\
\hline & Very severe & $930 \pm 23.7$ & $7.1 \pm 5.5$ \\
\hline \multicolumn{2}{|c|}{ Statistical test value $^{\mathrm{KW}}$} & 14.73 & 9.60 \\
\hline \multicolumn{2}{|c|}{ p-value* } & 0.001 & 0.01 \\
\hline
\end{tabular}

$K W=$ Kruskal Wallis test.

*statistically significant at p-value $<0.05$.

Table3. Intercorrelations between IL-8 and the predictor variables.

\begin{tabular}{|l|c|c|c|c|}
\hline & Age & Gender & Severity of disease & Duration of disease \\
\hline IL-8 & -0.18 & 0.06 & $0.63^{* *}$ & $0.29^{* *}$ \\
\hline Age & & -0.08 & -0.14 & $0.21^{*}$ \\
\hline Gender & & & -0.01 & -0.09 \\
\hline Severity of disease & & & & $0.74^{* *}$ \\
\hline Duration of disease & & & & \\
\hline
\end{tabular}

$*$ p-value $<0.05$

$* * p$-value $<0.01$ 
Rania H E. Mohammed et al.

Table4. Intercorrelations between CRP and the predictor variables.

\begin{tabular}{|l|c|c|c|c|}
\hline & Age & Gender & Severity of disease & Duration of disease \\
\hline CRP & -0.14 & 0.08 & $0.71^{* *}$ & $0.30^{* *}$ \\
\hline Age & & -0.07 & -0.13 & $0.25^{*}$ \\
\hline Gender & & & -0.02 & -0.08 \\
\hline Severity of disease & & & & $0.64^{* *}$ \\
\hline Duration of disease & & & & \\
\hline
\end{tabular}

$*$ p-value $<0.05$

$* *$-value $<0.01$

Table5. Multiple regression analysis summary for age, gender, severity of disease and duration of disease predicting IL-8 level.

\begin{tabular}{|l|c|c|c|c|}
\hline & B & St error of B & Beta ( $\beta)$ & p-value* \\
\hline Age & 3.05 & 7.71 & 0.04 & 0.69 \\
\hline Gender & 23.38 & 63.49 & 0.03 & 0.71 \\
\hline Severity of disease & 191.29 & 31.03 & 0.94 & 0.001 \\
\hline Duration of disease & -45.57 & 17.16 & -0.41 & 0.01 \\
\hline Constant & -116.19 & 202.38 & & 0.57 \\
\hline
\end{tabular}

Note: $R^{2}=0.43, F(4.64)=13.82, p<0.001$.

* Significant at p-value $<0.05$

Table6. Multiple regression analysis summary for age, gender, severity of disease and duration of disease predicting CRP level.

\begin{tabular}{|l|c|c|c|c|}
\hline & B & St error of B & Beta ( $\beta)$ & p-value* $^{*}$ \\
\hline Age & 2.05 & 6.51 & 0.03 & 0.78 \\
\hline Gender & 32.28 & 56.59 & 0.02 & 0.65 \\
\hline Severity of disease & 292.39 & 32.03 & 0.93 & $<0.001$ \\
\hline Duration of disease & -46.47 & 15.15 & -0.42 & 0.01 \\
\hline Constant & -126.18 & 301.37 & & 0.58 \\
\hline
\end{tabular}

Note: $R^{2}=0.42, F(3.67)=12.83, p<0.001$.

* Significant at p-value $<0.05$

\section{DISCUSSION}

Sebum overproduction due to sebaceous gland hyperplasia occurs firstly in IAV [17]. Also, the hair follicle hyperkeratinizes and prevents normal shedding of the follicular keratinocytes. Subsequent obstruction of the follicle forms an unapparent microcomedo. Thus, lipids and cellular debris accumulate within the blocked follicle [18]. Colonization of $P$. acne is encouraged by this microenvironment and provokes the immune response after production of numerous inflammatory mediators. Follicular rupture, leakage of lipids, bacteria and fatty acids into the dermis enhances inflammation.

Vowels et al., [19] and Chen et al [20] demonstrated that $P$. acnes induced IL-8 production, which is one of the main proinflammatory mediators produced by monocytes [21]. IL-8 gene is the one most highly induced by all bacterial stimulants [22]. So, IL-8 is the key proinflammatory mediator in innate immunity against bacteria by inducing a profound neutrophil chemoattraction. Lim et al also showed that CRP highly produces cytokines such as TNF- $\alpha$, IL-1, IL- 6 and IL-8 from monocytes [23]. IL-8 plays a key role in the initiation of vascular inflammation [6-8]. CRP not only can induce IL-8 mRNA and potentiates secretion elevation from human blood monocytes, but also affects the whole circulation to increase the IL-8 level [13]. Data from this study pointed out the increased level of IL-8 and CRP in the serum of patients with IAV versus healthy subjects indicating the pivotal role of inflammation in IAV. Results of this study agreed with previous studies which showing that IL-8 was released by a different of cell types including monocytes, macrophages, $\mathrm{T}$ lymphocytes, fibroblasts, endothelial cells and keratinocytes in response to inflammatory stimuli [3, 22, 24].

IL-8 attracts and degranulates neutrophils [25, 26]. Subsequently; potential key regulators of cell signaling released as cathepsin $\mathrm{G}$, serine proteases, proteinase and leucocyte elastase at sites of inflammation. This followed by activating different IL-8 receptors [27]. This point was supported in the present study by the presence of a highly significant moderate positive correlation $(r=0.36, p=$ 0.003 ) between the severity of acne and IL-8 level was found. This agreed with Zhong-yong and his colleagues [28] 
Kim et al. [29] reported that toll-like receptor 2 (TLR-2) has been implicated in the pathogenesis of IAV. TLR-2 was activated by $P$. acnes. When bound, TLR-2 activated a transcription factor that up regulates production and the release of proinflammatory cytokines like IL-12 and IL-8 from monocytes. TLR-2 was expressed on infiltrating inflammatory cells around the pilosebaceous follicle. Its expression increased as the acne lesion ages and became more inflamed. This agreed with result of our study, as there was a significant weak positive correlation between duration of disease and IL-8 level. In contrast to this study; Abd El All et al [30] reported that the duration of the disease was not affected by IL-8 expression. In 2005 Nagy et al explained activation of TLR-2 and hypothesized that $P$. acnes induced IL-8 secretion could have a key role in initiation of inflammatory events in acne by attracting neutrophils to the site of active lesions [31]. Also, CRP in the studied groups was found statistically significant elevation and also there was statistical significance correlation between CRP elevation and severity of the disease. On the other hands, these results disagreed with Vergou $\mathrm{T}$ et al [16]. Thus, both high elevation of IL-8 and CRP had pivotal role in sever form of IAV.

\section{Conclusion}

IL-8 and CRP are proportionally correlates to the severity of inflammatory acne vulgaris. Its presence in IAV may contribute to the host defenses against $P$. acnes as well as to tissue damage through its various actions of the involved immune cells and inflammatory mediators. Targeted therapy to block IL-8 and CPR production may hold promise in limiting the deleterious effects of IL- 8 and CPR mediated inflammatory response.

\section{REFERENCES}

[1] Adityan B, Kumari R, Thappa DM. Scoring systems in acne vulgaris. Indian J Dermatol Venereol Leprol. 2009; 75:323-326.

[2] Kim J, Ochoa MT, Krutzik SR, et al. Activation of toll-like receptor 2 in acne triggers inflammatory cytokine responses. J Immunol. 2002 Aug 1; 169(3):1535-41.

[3] Vowels BR, Yang S, leyden JJ. Induction of proinflammatory cytokines by a soluble factor ofPropionibacterium acnes: implications for chronic inflammatory acne. Infect Immunity 1995; 63:3158-65.

[4] Okamura H, Nagata K, Komatsu T, et al. A novel costimulatory factor for gamma interferon induction found in the livers of mice causes endotoxic shock. 1995; h3 (10): 3966-72.

[5] Yoshimura T, Matsushima K, Oppenheim J, Leopard EJ. Neutrophil chemotactic factor produced by lipopolysaccharide (LPS)-stimulated human blood mononuclear leukocytes: partial characterization and separation from interleukin-1 (IL-1). J Immunol 1987; 139:788-93.

[6] Hoch RC, Scraufstatter IU, Cochrane CG. In vivo, in vitro, and molecular aspects of interleukin-8 and the interleukin-8 receptors. J Lab Clin Med 1996; 128:134-45.

[7] Baggiolini M, Dewald B, Moser B. Human chemokines:an update. Annu Rev Immunol 1997;15:675-705.

[8] Matsukawa A, Yoshimura T, Maeda T, Ohkawara S, Katsumasa T, Yoshinaga M. Neutrophil accumulation and activation by homologous IL-8 in rabbits. J Immunol 1995; 154 : 5418-23.

[9] Pepys MB, Hirschfield GM. C-reactive protein: a critical update. J Clin Invest. 2003 Jun; 111(12):1805-12.

[10] Liu S, Ren J, Xia Q, et al. Preliminary Case-control Study to Evaluate Diagnostic Values of CReactive Protein and Erythrocyte Sedimentation Rate in Differentiating Active Crohn's Disease from Intestinal Lymphoma, Intestinal Tuberculosis and Behcet's Syndrome. Am J Med Sci. 2013 Dec;346(6):467-72.

[11] Colina M, Govoni M, Orzincolo C, Trotta F. Clinical and radiologic evolution of synovitis, acne, pustulosis, hyperostosis, and osteitis syndrome: a single center study of a cohort of 71 subjects. Arthritis Rheum. 2009 Jun 15;61(6):813-21.

[12] Hurtado-Nedelec M, Chollet-Martin S, Nicaise-Roland P, et al. Characterization of the immune response in the synovitis, acne, pustulosis, hyperostosis, osteitis (SAPHO) syndrome. Rheumatology (Oxford). 2008 Aug; 47(8):1160-7. 
[13] Xie L, Chang L, Guan Y, Wang X. C-reactive protein augments interleukin8 secretion in human peripheral blood monocytes. J Cardiovasc Pharmacol. 2005 Nov;46(5):6906.

[14] Dréno B, Poli F, Pawin H, et al. Development and evaluation of a Global Acne Severity Scale suitable for France and Europe J Eur Acad Dermatol Venereol. 2011; 25(1):43-8.

[15] Brown KJ. A novel in vitro assay for human IL-8 angiogenesis. Laboratory Investigation. 1996; 75: 539-555.

[16] Vergou T, Mantzou E, Tseke P, et al. Association of thyroid autoimmunity with acne in adult women. J Eur Acad Dermatol Venereol. 2012 Apr; 26(4):413-6.

[17] Gollnick HP, Zouboulis CC, Akamatsu H, Kurokawa I, Schulte A. Pathogenesis and pathogenesis related treatment of acne. J Dermatol1991, 18:489-499.

[18] Holmes RL, Williams M, Cunliffe WJ. Pilo-sebaceous duct obstruction and acne. Br J Dermatol1972, 87:327-332.

[19] Vowels BR, Yang S, and Leyden JJ. Induction of Proinflammatory Cytokines by a Soluble Factor of Propionibacterium acnes: Implications for Chronic Inflammatory Acne. American Society for Microbiology. 1995. Vol. 63, No. 8: p. 3158-3165.

[20] Chen Q, Koga T, Uchi H, et al. Propionibacterium acnes-induced IL-8 production may be mediated by NF-k $\beta$ activation in human monocytes. J Dermatol Sci. 29 (2002) $97-103$.

[21] Wang ZM, Liu C, Dziarski R. Chemokines are the main pro-inflammatory mediators in human monocytes activated by Staphylococcus aureus, peptidoglycan, and endotoxin. J Biol Chem 2000; 275:20260-7.

[22] Sticherling M, Bornscheuer E, Schroder JM, Christophers E. Localization of neutrophilactivating peptide-1/interleukin-8-immunoreactivity in normal and psoriatic skin. J Invest Dermatol1991, 96:26-30.

[23] Lim MY, Wang H, Kapoun AM, et al. p38 inhibition attenuates the proinflammatory response to C-reactive protein by human peripheral blood mononuclear cells.J Mol Cell Cardiol. 2004; 37:1111-1114.

[24] Li A, Dubey S, Varney ML, Dave BJ, Singh RK. IL-8 directly enhanced endothelial cell survival, proliferation, and matrix metalloproteinases production and regulated angiogenesis. $\mathbf{J}$ Immunol 2003, 170:3369-3376.

[25] Beaubien BC, Collins PD, Jose PJ, et al. A novel neutrophil chemoattractant generated during an inflammatory reaction in the rabbit peritoneal cavity in vivo. Purification, partial amino acid sequence and structural relationship to interleukin 8. Biochem J1990, 271:797-801.

[26] Collins PD, Jose PJ, Williams TJ. The sequential generation of neutrophil chemoattractant proteins in acute inflammation in the rabbit in vivo. Relationship between C5a and proteins with the characteristics of IL-8/neutrophil-activating protein 1. J Immunol1991, 146:677-684.

[27] Wiedow O, Meyer-Hoffert U: Neutrophil serine proteases. Potential key regulators of cell signalling during inflammation. J Intern Med2005, 257:319-328.

[28] Zhong-Yong W, Kan LI, Pan-pan QIU, Hui-fen QIU, Chun-mei SHU and GAO Yu. Expression of TLR2 in peripheral blood mononuclear cells and its correlation with interleukin-8 and tumor necrosis factor- $\alpha$ in patient with acne vulgaris. Chinese Journal of Dermatology. ; 2011, 44(2) 121-123.

[29] Kim J, Ochoa M T, Krutzik S R. Activation of toll-like receptor 2 in acne triggers inflammatory cytokine responses. J Immunol; 2002, 169: 1535-1541.

[30] Abd El All HS, Shoukry NS, El Maged RA, Ayada MM. Immunohistochemical expression of interleukin 8 in skin biopsies from patients with inflammatory acne vulgaris. Diagn Pathol; 2007, 2: 4-7.

[31] Nagy I, Pivarcsi A, Koreck A, Szell M, Kemeny L. Distinct strains of Propionibacterium acnes induce selective human beta-defensin-2 and interleukin- 8 expression in human keratinocytes through toll-like receptors. J Invest Dermatol: 2005, 124: 931-938. 